\title{
Challenges of the Rehabilitation of Two Central Incisors
}

\author{
*Carlos Eduardo Sorgi da Costa and Mario Kawagoe \\ ${ }^{1}$ Specialist in Prosthodontics, Universidade Estadual Paulista UNESP, Brazil \\ ${ }^{2}$ Coordinator of the Specialization Course in Prosthodontics, CETAO Institute São Paulo, Brazil
}

Submission: February 18, 2017; Published: September 06, 2017

*Corresponding author: Carlos Eduardo Sorgi da Costa, Specialist in Prosthodontics, Universidade Estadual Paulista UNESP, Brazil, Email: eduardosorgi@gmail.com
Abstract
The constant advancement of ceramic systems, influencing the equilibrium of a highly aesthetic material with satisfactory resistance properties, together with the advances and successes of the adhesion systems, are increasingly encouraging patients who seek an aesthetic solution with longevity.
Careful planning based on refined diagnostic waxes, with cross-information with complete photographic planning, shows that it is.
It is possible to carry out a great rehabilitation with great predictability and safety in details that make a total difference in the final result. In this case report we show a total harmonization of the smile of a young patient who was very satisfied with the results obtained.
Keywords: Implant; Ceramic restorations; Bone graf

\section{Introduction}

The harmony, naturalness and aesthetics of a smile represents the reason of extreme interest during the rehabilitation treatment, since it will also be the reason for personal satisfaction, safety and balance for a lifetime. After identifying a problem in an interceptive way, still in adolescence, it is necessary a careful and meticulous planning so that the final result of the work has the guarantee of longevity and naturalness for the patient (Figure $1 \& 2$ ).

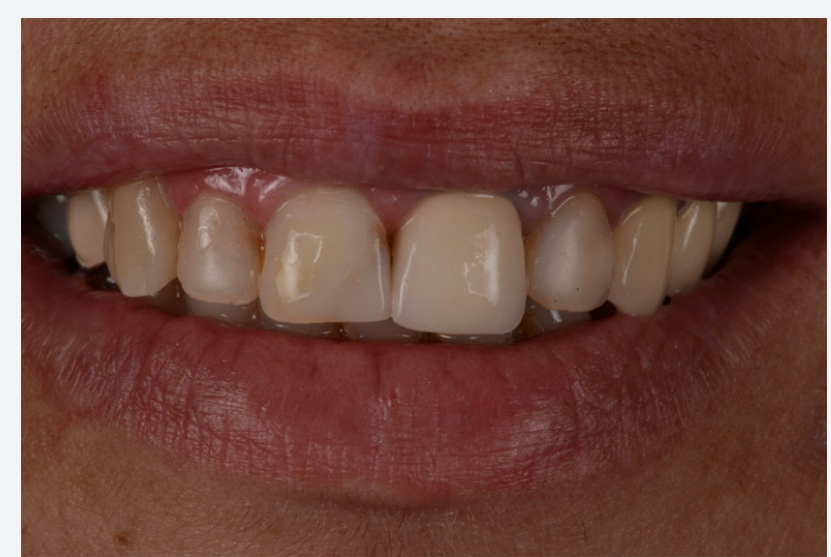

Figure 1: Initial smile Figure.

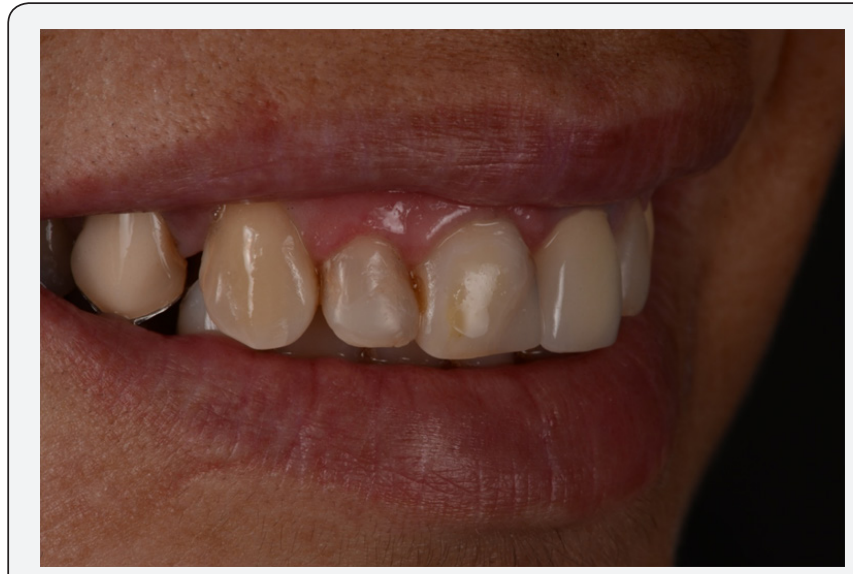

Figure 2: Figure of the lateral smile profile.

Dentistry shows that in most cases patients are not satisfied with the final outcome after rehabilitation. Even because often this rehabilitation transpires a prosthesis and the result so dreamed by the patients would be a tooth very close to the natural, or glimpsing a harmony of any set that does not represent artificiality.

The great challenge, therefore, is to reconstruct beyond the absence of the teeth, as well as the recovery of the lost tissues, 
since the handling of these tissues to the ceramic restoration can represent the differential that will seek naturalness and perfection.

A root fracture associated with trepanation after endodontic treatment has a poor prognosis and the extraction of the dental element in question becomes the clinical solution, since this situation may present besides the discomfort, inflammatory reaction and possible development of lesions in the problematic regions.The customized abutment provides stability to the fabrics, with aesthetic requirements, especially in the anterior region, where this fabric is often very thin (Figure 3-6).

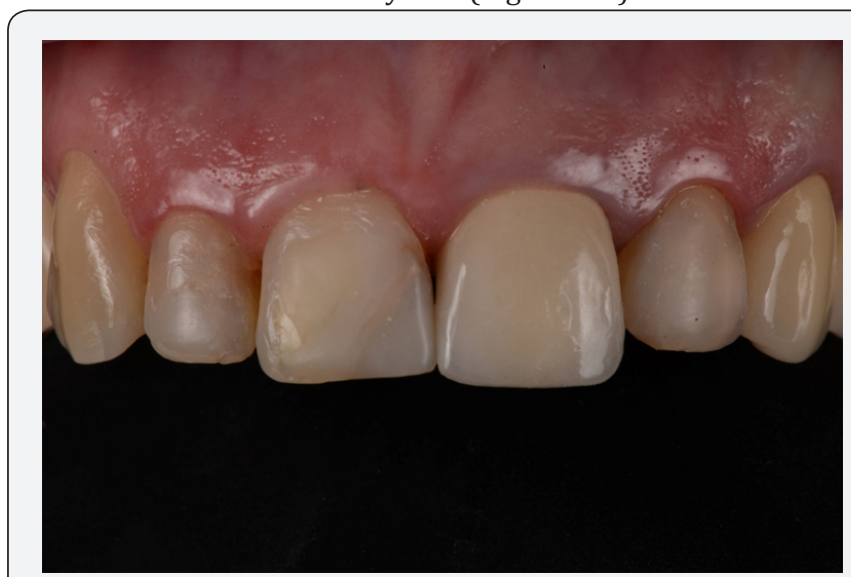

Figure 3: Initial smile with contrast.

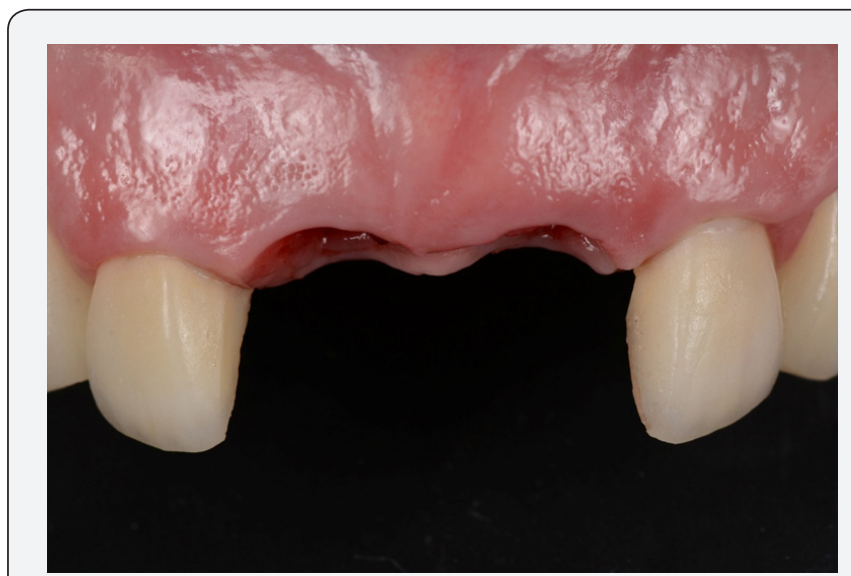

Figure 4: Thirty days after minimally invasive extraction.

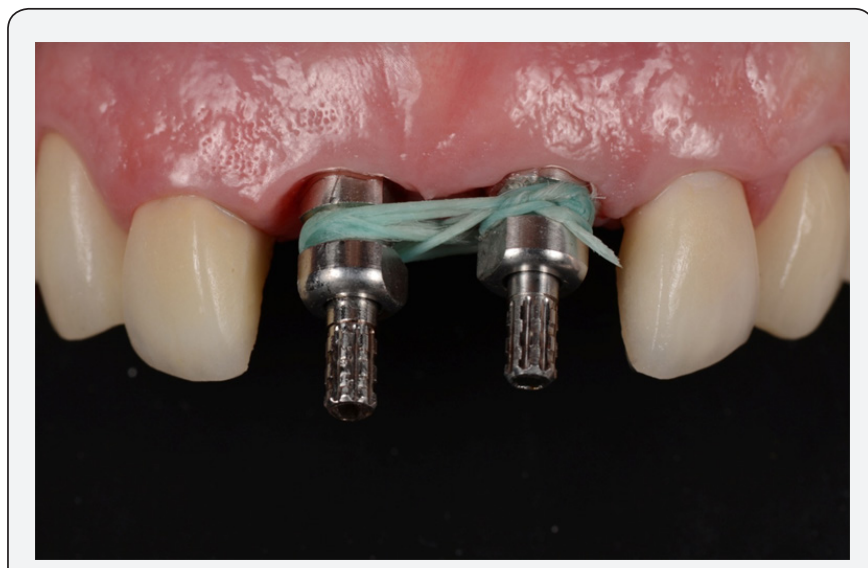

Figure 5: Transfer installation.

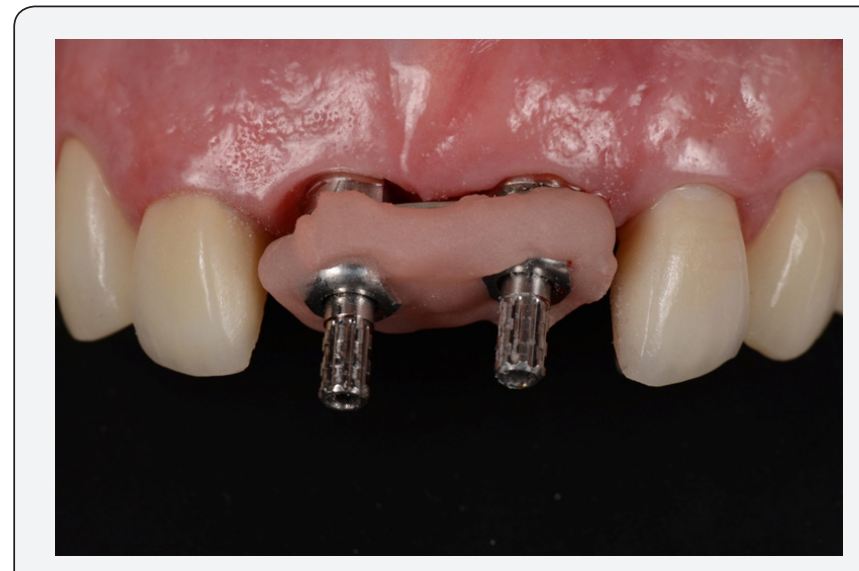

Figure 6: Union of transfers.

Starting from this protocol, a rehabilitation was planned that involves the installation of small diameter implant, ideal for the region, design of the gingival architecture through the customization of the temporary and aesthetic and personalized pillars for maintenance of the gingival tissue around the implant.

\section{Discussion}

The general change of a patient's smile interferes positively in every psychological and social aspect of the patient who shows total dissatisfaction with his appearance.So that the final result of the treatment can surprise and present in addition to incredible aesthetic results, also function and precision adaptation to provide gum health as well as harmony of the whole set, it is necessary the planning based on previous diagnostic waxing and photographic planning. Cross-referencing this information will lead to a predictable and safe conduct in this type of rehabilitation work (Figure 7).

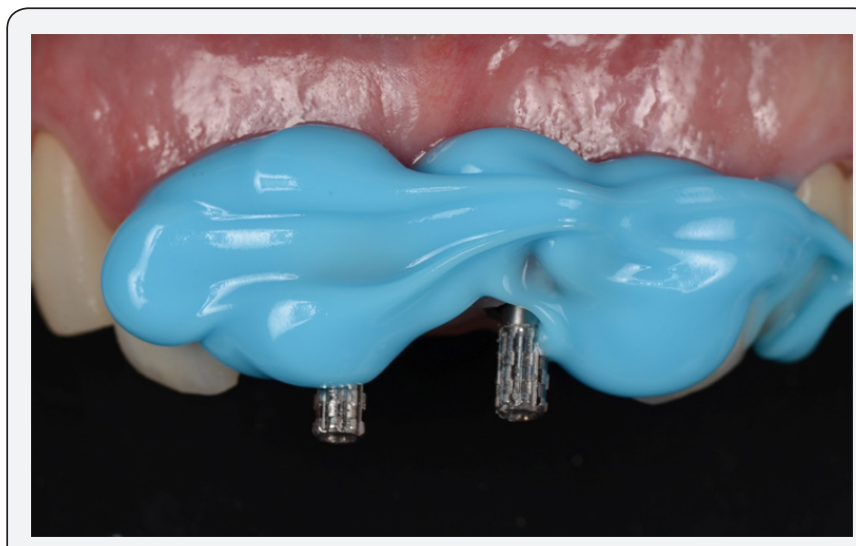

Figure 7: Addition silicone molding.

The success of ceramic restorations on implants depends directly on several factors that begin in the surgical planning and are directed until the moment of installation of the prosthesis. Implants are now well established in terms of success and osseointegration. The ceramics are modern and have incredible properties in relation to aesthetic factors. Therefore, the great challenge is to achieve integration and naturalness in the transition line between implant, soft tissue and ceramic prosthesis. The contour and papillary support in this region is somewhat delicate 


\section{Advances in Dentistry \& Oral Health}

and its attainment depends on planning and a thorough approach on surgery and tissue conditioning.This clinical case was treated after a cautious clinical and tomographic diagnosis, thus, a conservative protocol for the surgical exodontia was respected (Figure 8-10).

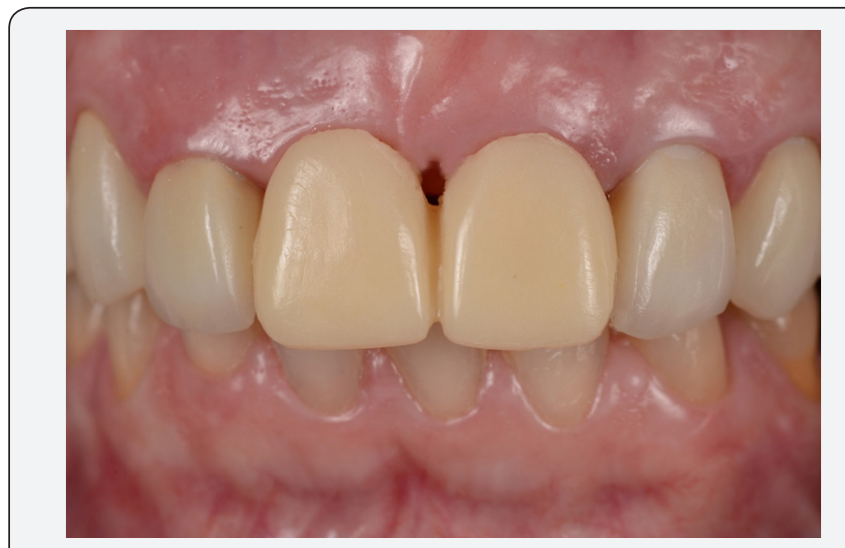

Figure 8: Tissue conditioning with provisional.

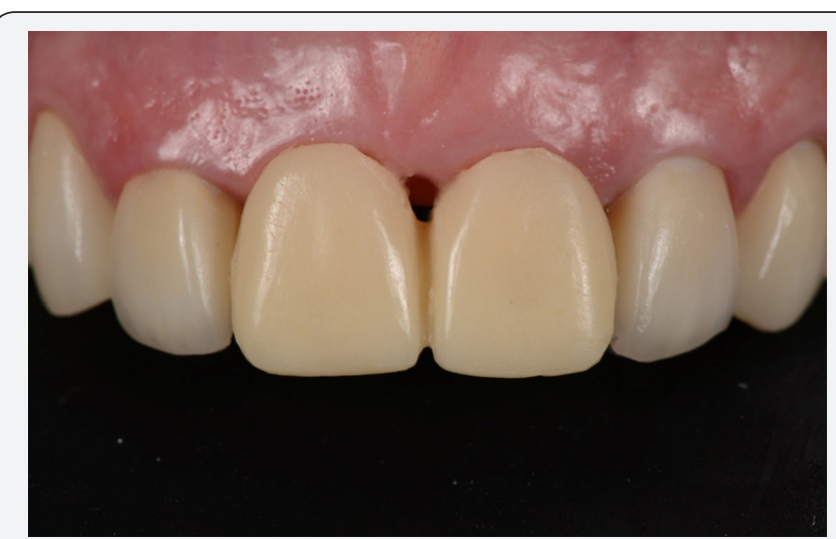

Figure 9: Five months with provisional.

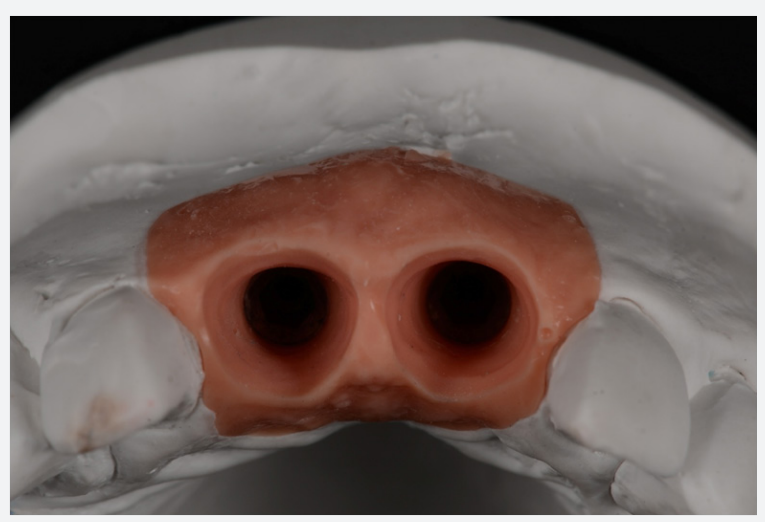

Figure 10: Model with emergency profile acquired.

The use of the root extractor allowed the integrity of the bone walls, maintaining the alveolus in conditions to receive an immediate implant. Normally, in the first eight weeks after extraction, vestibular bone tissue undergoes an important process of resorption in cases where only the clot is maintained. In this situation, an implant with a small diameter of $3.25 \mathrm{~mm}$ was chosen, both because the space is reduced in the region of the lower central incisor, and also to ensure a better emergence profile and accommodation of the papillae around the neck of the implant (Figure $11 \& 12$ ).

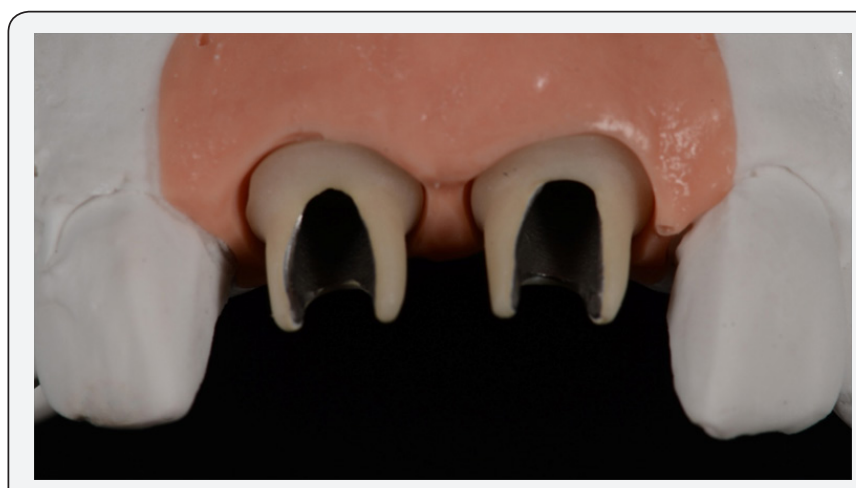

Figure 11: Custom Abutments.

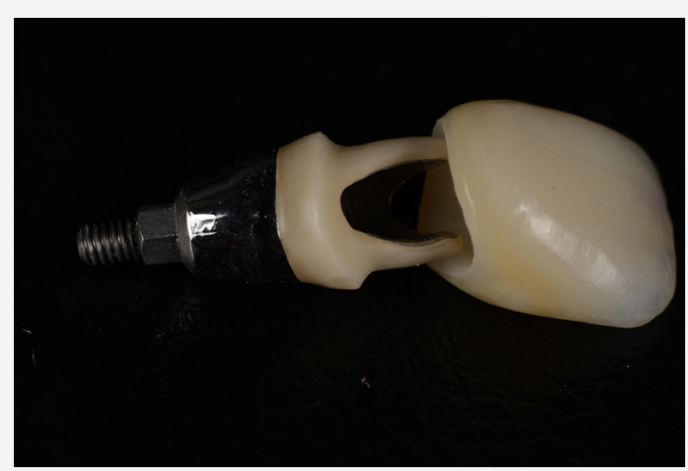

Figure 12: Ceramic Crown made by E - Max Ivoclar Vivadent System

It is possible to observe better bone maintenance and greater tissue control in anterior region surgeries with atraumatic exodontia of the dental element, immediate implant installation without flap opening and bone graft with biomaterial to fill the gap between implant and bone wall, with the same purpose the Implants are small in diameter and installed below the marginal bone crest.

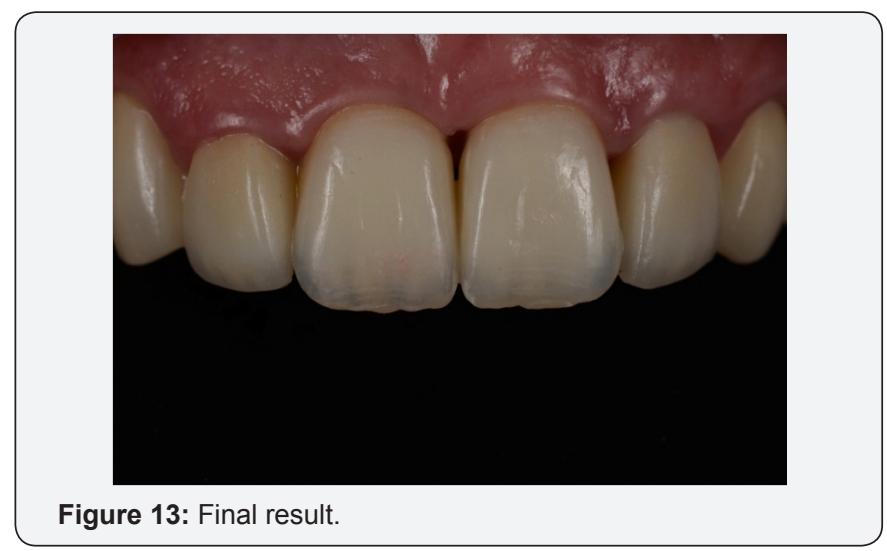

The cervical finish of the ceramics, precise adaptation to the abutment respecting the proper spaces, has direct connection with 
gingival health. This cervical contour is of extreme importance both aesthetically and biologically (Figure 13).

Final Considerations: With careful planning it is possible to obtain a highly esthetic result in prosthesis on implants. Some care during the surgical procedure such as minimally invasive exodontia with root extractor use, immediate implantation of the implant favor the success in this type of treatment. The customization of the temporary and tissue manipulation to create an emergency profile and gingival architecture are details that will make a great difference, presenting naturalness and harmony in this type of rehabilitation (Figure 14).

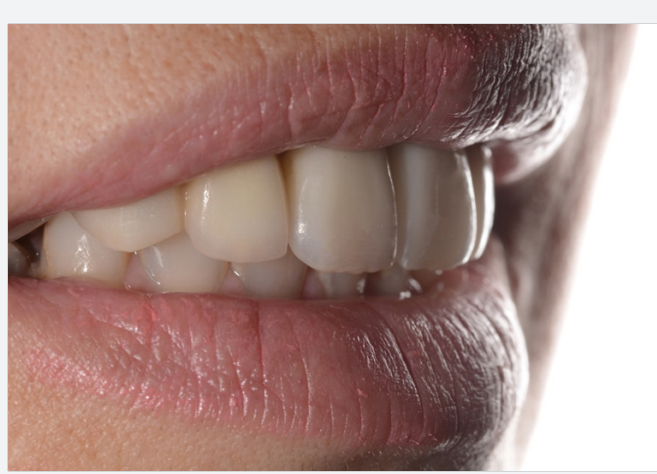

Figure 14: Harmony of the final smile.

Your next submission with Juniper Publishers will reach you the below assets

- Quality Editorial service

- Swift Peer Review

- Reprints availability

- E-prints Service

- Manuscript Podcast for convenient understanding

- Global attainment for your research

- Manuscript accessibility in different formats

( Pdf, E-pub, Full Text, Audio)

- Unceasing customer service

Track the below URL for one-step submission https://juniperpublishers.com/online-submission.php 